\title{
CHAPTER 1 \\ Complexity of Life and Its Dependence on the Environment
}

\author{
Werner Arber
}

Summary Because of the extensive scientific research carried out over the past 200 years, mainly in biology, astrophysics and geology, we have obtained increasingly better insights into the ongoing evolution of living organisms and their habitats. We have thereby acquired information on the complexity of life and its dependence on the environment, which lead us to better appreciate the need to safeguard the high diversity of both living organisms and their environments. On the one hand, all living organisms interdepend on their cohabitation with other kinds of organisms. On the other hand, the slowly changing living conditions of habitats require a living species to occasionally undergo appropriate genetic variation. Ongoing research projects continue to provide insight into evolutionary processes, which are carried out in nature by self-organization, taking care to safeguard a relatively high genetic stability and also ensuring occasional variations of living conditions and their inhabitants. The human population on our planet should avoid intervening in these naturally ongoing evolutionary processes to ensure high biodiversity and its sustainable long-term development.

\section{Introduction}

In the 1940s, scientific research revealed that the phenotypes of living organisms depend on the genetic information carried in their genomes. In subsequent decades, it became more clear that life activities also depend on environmental conditions,

Nobel Laureate, Medicine/Physiology 1978.

W. Arber $(\bowtie)$

Molecular Microbiology, Biozentrum, University of Basel, Basel, Switzerland

e-mail: werner.arber@unibas.ch 
including the living and material compositions of the habitats and various temporal impacts from the wider environment. We therefore realize that living organisms depend on both their own genetic information and various environmental conditions. The latter also exert their impact on biological evolution at the population level.

\section{Symbiosis and Nutritional Interdependencies}

The cohabitation of various kinds of living organisms can greatly facilitate the life of individual organisms. Human beings and many other eukaryotic organisms are known to strongly depend on cohabiting microorganisms in so-called microbiomes (Blaser, Bork, Fraser, Knight, \& Wang, 2013). Thereby, various kinds of bacteria live in symbiosis with humans, animals or plants. Their hosts provide nutrition to the cohabiting bacteria, and the bacteria help their hosts in food digestion and other essential functions. In contrast, several pathogenic microorganisms, both bacteria and viruses, occasionally infect human beings and eukaryotic animals, making them ill. However, we have to be aware that only a minority of bacteria are pathogenic, whereas beneficial microbiomes permanently contain a large number of nonpathogenic bacteria.

Another obvious interdependency resides in the provision of nutrition to other kinds of organisms. Wild animals generally gather and hunt their food in their habitats. To improve their lives, about 10,000 years ago, human beings started to domesticate food plants and animals, which is known as agriculture. Until relatively recently, agriculture was mostly carried out manually on a small scale.

\section{Impacts of Nonliving Environmental Factors on Terrestrial Life Conditions}

Many living organisms depend, to some degree, on environmental factors such as climate, temperature, solar radiation, air pollution and weather conditions. These can vary over the course of time both intrinsically and due to the impacts of human activities. Some of these interdependencies caused by human civilization strengthen the negative impacts on the living conditions and thus also on the lives of individual beings. However, it can be quite difficult to ameliorate the situation on a global level. 


\section{Value of High Biodiversity}

As a result of the long history of biological evolution, our planet benefits from a high diversity of species. As a consequence, any habitat usually contains a relatively high number of different species, and this richness can be quite beneficial for the cohabiting species. For this reason, as well as for other reasons (to be explained below), our civilization should avoid causing any negative impact on this rich biodiversity, which would also affect human life, as shown by the following two examples.

Occasionally, a segment of genetic information can be horizontally transferred from one kind of organism to another, where it can become a part of the genome and exert its activities. Horizontal gene transfer is one of the natural strategies of biological evolution (see below). It is obvious that the loss of rich biodiversity can reduce the available genetic information and thus also affect the biological evolution of other kinds of organisms.

Advancements in scientific knowledge can reveal previously unknown biological potentials of a member of the biodiversity. In order not to lose such a function upon a future extinction of the species in question, one can try to save this genetic potential by transferring it in the laboratory into another kind of organism, which can be expected to express the gene product under consideration. This can allow the investigators to isolate a product that might contribute to a technological advance for our civilization. A striking example is the horizontal transfer of the genetic potential of some spiders into appropriate bacteria to produce silk-like fibres (Rech \& Arber, 2013).

\section{Insight into the Laws of Nature for Biological Evolution}

Biological evolution is a very slow, continual process; it cannot be easily perceived. As a result of the intensive research on bacterial populations, a number of molecular mechanisms are known to occasionally produce genetic variants and thus contribute to biological evolution after natural selection of mutants that demonstrate a functional improvement for living in their habitat, or sometimes for adapting to an alternative habitat. One can assign the identified individual molecular mechanisms of mutagenesis to just a few natural strategies of biological evolution (Arber, 2007). According to our knowledge to date, one of these strategies is based on local mutagenesis affecting one or a few adjacent nucleotides in the genome. The second strategy of spontaneous mutagenesis involves a genomic segment, which can become transposed, duplicated, deleted or inversed in the genome. Finally, the third strategy is based on the previously mentioned horizontal gene transfer, which allows a recipient organism to acquire a functional genome segment from a donor organism. This acquisition of foreign genetic information is a very efficient process because of the universal genetic code (i.e., the common language of different kinds of organisms). 
For some of these mutagenesis events, the products of so-called evolution genes carried in the genome are involved in intragenomic DNA rearrangements. Other evolution genes limit the frequency of mutagenesis events. Some other mutagenesis processes result from the impacts of nongenetic factors, such as environmental mutagens, short-living isomeric forms of biologically active molecules or random encounters. We are aware that Mother Nature only rarely causes a spontaneous genetic variation, so the genetic potential of most individuals in a given population remains preserved. The aforementioned mutagenesis processes occur mostly randomly on the genome and randomly in time. Therefore, only a minority of novel genetic variants reveal, upon natural selection, a functional improvement.

\section{Improvement of Life Expectancy}

The knowledge acquired from intensive biological and technological research over the past 200 years has considerably improved human health and various human life facilities, including communication, travelling and the procurement of food. In only a few decades, biomedical knowledge and its applications have resulted in considerably increased human life expectancy, particularly in developed countries. It is our duty to help populations in developing countries, which often have high rates of child mortality, to also benefit from this available biomedical knowledge.

To the best of our knowledge, all living organisms have a statistical average of life expectancy. Genetic alterations or behavioural or environmental impacts can occasionally increase the life expectancy of a given species to some extent. This has recently led to discussions about the possibility of providing immortality to living organisms (including Homo sapiens), i.e., an eternal life (Knell \& Weber, 2009; Die Frage nach der Zukunft, 2017). In my point of view, this goal is not compatible with the wonderful natural process in which biological evolution helps a species adapt to changing living conditions.

\section{Improvement of Nutritional Diets for Better Health}

It is well known that an appropriate diet provides our body with the energy required for our daily activities. The lack of a nutritional source of energy is felt as hunger. It has lately also become known that various biological activities may require socalled micronutrients, such as vitamins or some chemical elements. The lack of an essential micronutrient causes so-called hidden (unfelt) hunger and can lead to an organic mis-development. An example is a deficiency in vitamin A, which is required for the proper neuronal development of a child, both during its embryonic development and during the first few years after birth (Potrykus \& Ammann, 2010). In this case, insufficient vitamin A leads to a neuronal mis-development that can cause the death of the child in its first few years or blindness. 
It is important for scientific researchers to explore other adverse health effects due to a lack of sufficient micronutrients. Such knowledge may prevent mis-developments by providing the necessary specific micronutrients in due time. Ideally, this goal can be reached by enriching commonly used food crops with the required micronutrients, thus preventing hidden hunger in the people in question.

\section{Intensive Agriculture or Protection of the Rich Biodiversity?}

As mentioned previously, agriculture has been carried out manually for a long time. In many countries, a shift has occurred in recent decades to use tractors with specialized machines for cultivation, maintenance, and harvesting of food crops. These cultivations are often combined with the use of herbicides or insecticides to remove other plants and insects from large monocultures of agricultural crops. This practice can contribute to severe reductions in the rich biodiversity.

\section{Reflection on Future Living Conditions on Our Planet Earth}

As we have already discussed, a steadily, but very slowly, progressing biological evolution has resulted in the current rich biodiversity. This permanent creation originated approximately 3500 million years ago with unicellular organisms. According to astrophysical theories, the Sun is expected to continue to provide energy to its planets for approximately 4000 million years. However, we do not know how long our planet Earth will exist and contain habitats that host different kinds of living organisms. Let us hope that human civilization in its rich biodiversity will have a time horizon of about 1 million years; during this period of time, biological evolution can be expected to steadily continue slowly. As we have seen, the natural strategy of horizontal gene transfer can provide qualitative improvements to evolving organisms. For this reason, it is important to maintain the rich biodiversity on our planet Earth. Future scientific investigations are expected to allow our civilization to reach this goal by preventing activities that lead to the partial extinction of species existing in the diversity of life. In addition, we should also take care not to entirely use up essential raw materials by our life activities.

\section{From Quantitative to Qualitative Growth}

Our planet Earth has a constant size and therefore a limited capacity to host living organisms. In view of the conceptual relevance of a rich biodiversity, a given species of living organisms should not overgrow other kinds of organisms. The aforementioned interdependence of different kinds of organisms, both for their life activities 
and for their biological evolution, is of high conceptual relevance to the living world. A logical conclusion from this insight is that no species should quantitatively overgrow the others. However, a qualitative growth would always be welcome. Applying this concept to the human population is of primary importance for the healthy long-term persistency of human civilization on our planet.

\section{Conclusion}

As members of the human species, we have the privilege of a high intellectual capacity. Thus, we realize that our life interdepends on the presence and activities of many other species of living organisms. Based on these long-term insights, the Christian religions attribute to Homo sapiens the role of a good shepherd of creation, who should take care of other kinds of organisms and their habitats. Following this conceptual task, we are expected to protect the presence of a rich diversity of other kinds of living organisms. This essential conclusion is based both on a religious tradition and on more recently acquired scientific knowledge.

As shepherds, we have the responsibility to protect the long-term living conditions of the planet, including the natural process of biological evolution. In addition, it is our task to bring the world view described here to the attention of all human beings on our planet. This requires a well-qualified education applied to human societies worldwide.

\section{References}

Arber, W. (2007). Genetic variation and molecular evolution. In R. A. Meyers (Ed.), Genomics and genetics (Vol. 1, pp. 385-406). Weinheim: Wiley-VCH.

Blaser, M., Bork, P., Fraser, C., Knight, R., \& Wang, J. (2013). The microbiome explored: Recent insights and future challenges. Nature Reviews Microbiology, 11, 213-217.

Die Frage nach der Zukunft. In: zur Debatte 4/2017. Themen und Tagungen der Katholischen Akademie, Bayern.

Knell, S., \& Weber, M. (2009). Menschliches Leben. Berlin, Germany: Walter de Gruyter.

Potrykus, I., \& Ammann, K. (Eds.). (2010). Transgenic plants for food security in the context of development. Special Issue of New Biotechnology, 27, 445-717.

Rech, E. L., \& Arber, W. (2013). Biodiversity as a source for synthetic domestication of useful specific traits. Annals of Applied Biology, 162, 141-144. 
Open Access This chapter is licensed under the terms of the Creative Commons Attribution 4.0 International License (http://creativecommons.org/licenses/by/4.0/), which permits use, sharing, adaptation, distribution and reproduction in any medium or format, as long as you give appropriate credit to the original author(s) and the source, provide a link to the Creative Commons license and indicate if changes were made.

The images or other third party material in this chapter are included in the chapter's Creative Commons license, unless indicated otherwise in a credit line to the material. If material is not included in the chapter's Creative Commons license and your intended use is not permitted by statutory regulation or exceeds the permitted use, you will need to obtain permission directly from the copyright holder. 